\title{
A flexible model for economic operational management of grid battery energy storage
}

\author{
Robert L. Fares ${ }^{1, *}$, Michael E. Webber ${ }^{1}$ \\ Department of Mechanical Engineering, The University of Texas, Austin, Texas 78712
}

\begin{abstract}
To connect energy storage operational planning with real-time battery control, this paper integrates a dynamic battery model with an optimization program. First, we transform a behavioral circuit model designed to describe a variety of battery chemistries into a set of coupled nonlinear differential equations. Then, we discretize the differential equations to integrate the battery model with a General Algebraic Modeling System (GAMS) optimization program, which decides when the battery should charge and discharge to maximize its operating revenue. We demonstrate the capabilities of our model by applying it to lithium-ion (Li-ion) energy storage operating in Texas' restructured electricity market. By simulating 11 years of operation, we find that our model can robustly compute an optimal charge-discharge schedule that maximizes daily operating revenue without violating a battery's operating constraints. Furthermore, our results show there is significant variation in potential operating revenue from one day to the next. The revenue potential of Li-ion storage varies from approximately $\$ 0-1800 / \mathrm{MWh}$ of energy discharged, depending on the volatility of wholesale electricity prices during an operating day. Thus, it is important to consider the material degradationrelated "cost" of performing a charge-discharge cycle in battery operational management, so that the battery only operates when revenue exceeds cost.
\end{abstract}

Keywords:

Energy storage, Battery, Economics, Optimization

*Department of Mechanical Engineering, The University of Texas at Austin, 204 E. Dean Keeton Street, Stop C2200, Austin, Texas 78712-1591. +1 (512) 471-7838.

Email address: robertfares@utexas.edu (Robert L. Fares) 


\section{Introduction}

Because of the high cost of conventional large-scale electricity storage technologies (such as pumped-hydro energy storage [1]), it has typically been more economical to produce electricity on demand, generating and then delivering it to the end user in real time. To reliably deliver electricity on demand, generation, transmission, and distribution equipment must have the capacity to serve peak electric load, which only occurs for a small portion of the year. Furthermore, electric generators must set aside reserve capacity for grid ancillary services to ensure electric supply consistently equals demand, even in the case of a contingency. These two aspects of today's electric grid represent a non-trivial component of the cost of electricity. At the same time, concerns about air pollution, sustainability, and anthropogenic climate change have driven an increase in the amount of intermittent renewable energy resources connected to the grid. Because of the grid's on-demand design, it would benefit from the integration of more flexible electricity resources as the penetration of intermittent resources increases [2].

Grid energy storage is an appealing technology because it temporally decouples electricity supply from demand, which means generation can occur at a time other than when there is demand. Doing so adds new flexibility to grid operations with the potential to reduce grid capital expenditures, integrate higher fractions of intermittent renewable energy, and increase electric reliability. For these reasons, recent advances in battery technology have driven renewed interest in grid-based battery energy storage. Nevertheless, batteries have only been sparingly implemented on the U.S. electric grid. In 2011, there were less than $140 \mathrm{MW}$ of batteries installed [3]. This fact can be attributed to the high cost of existing battery systems and uncertainty surrounding the revenue potential of battery energy storage operating on the electric grid.

The revenue potential of grid battery energy storage is uncertain for primarily two reasons. First, because a battery cannot store electricity without incurring energy losses and material degradation from electrochemical conversion, the performance and lifetime of a battery in grid applications is uncertain. Second, because an energy storage plant uses grid electricity as its "fuel," the external price of electricity has a strong effect on its revenue potential. To generate revenue from the sale of electric energy, a grid battery must charge when the real-time price of electricity is low and discharge when the price is high. Thus, the profit maximization problem for a grid 
battery system is considerably more difficult than the profit maximization problem for a conventional power plant. For these reasons, it is desirable to develop a tool that integrates two features: 1) a battery model capable of describing complex battery performance characteristics within a real-time control framework, and 2) a decision-making framework to show how a battery should operate to maximize its revenue potential from the sale of electric energy.

To augment the existing literature, this paper connects a behavioralcircuit model capable of describing nonlinear battery performance characteristics with an optimization algorithm for grid battery operational management. The remainder of this paper is organized as follows: Section 2 reviews past literature that has sought to develop models to describe battery performance and manage the operation of grid energy storage. Section 3 discusses how we discretize a dynamic behavioral circuit model from the literature for use with optimization. Section 4 describes the formulation of a model-based optimization problem for operational management of grid battery storage, and application of the model to simulate lithium-ion (Li-ion) battery energy storage used for wholesale energy arbitrage in Texas' restructured ${ }^{1}$ electricity market. Section 5 shows the results of our case study, and discusses the implications of our results for economic operational management of a grid battery. Finally, Section 6 draws conclusions from our results and proposes future work.

\section{Background}

\subsection{Battery modeling}

Researchers have developed a number of models to describe a battery. These models can be broadly classified into two major categories: firstprinciples electrochemical models and empirical behavioral models. Firstprinciples models use physical equations to describe the transport and reaction of active species inside a battery. They describe how the concentration of active species at the electrode surface affects the overpotential required to drive an electrochemical reaction to store or release energy $[4,5,6,7,8]$. Empirical behavioral models use mathematical equations or physical analogs

\footnotetext{
${ }^{1}$ Modern competitive electricity markets are often described as "deregulated," despite the fact that numerous regulations still exist. This work will use the term "restructured" to describe competitive electricity markets.
} 
(e.g. electric circuits) to describe the system-level characteristics of a battery, such as capacity, efficiency and voltage. Peukert's law, which describes the relationship between rate of discharge and discharge capacity, is one of the earliest empirical models $[9,10]$. Other models describe a battery's non-linear capacity/recovery effects [11, 12, 13, 14], or energy efficiency [15]. Many empirical models use an electric circuit analog to describe the systemlevel behavior of a battery using a combination of variable voltage sources, resistors, and capacitors. A number of these models have been developed in the literature including Thévenin equivalent circuit models [16, 17, 18], impedance-based models [19, 20, 21], and runtime-based models [22, 23]. More recent electric circuit analog models combine the benefits of many of these models to empirically describe a number of complex battery characteristics $[24,25]$.

Empirical models are advantageous for real-time battery control because they can be designed to describe complex battery characteristics without significant computational complexity. In particular, electric circuit analog models have proven to be a flexible tool for empirically describing battery performance under diverse operating conditions, including temperature, state of charge, and charge-discharge rate [24, 25, 26, 27, 28, 29]. These models describe a battery's open circuit voltage using a variable potential source, and then use a combination of series resistors and parallel resistor-capacitor couples to describe a battery's ohmic potential drop and dynamic voltage behavior at various time scales. Numerous studies have developed methods to experimentally extract the electrical parameters required to describe a battery's dynamic state using these models [24, 28, 29, 30, 31].

\subsection{Operational management of grid energy storage}

A number of researchers have sought to analyze the value of electricity storage in the context of restructured electricity markets. Early studies use simple assumptions about energy storage system performance, operating revenue, and cost to assess the value of electricity storage in a restructured electricity market from a largely qualitative perspective [32, 33, 34]. More recent studies utilize multiple years of dynamic electricity price data that have become available since restructured electricity markets opened to quantitatively assess the value of electricity storage $[35,36,37,38,39,40,41,42,43$, $44,45,46,47,48]$. Typically, studies focus on assessing the techo-economic performance of one specific technology in a given market and system context using optimization and other techniques for energy storage operational 
management.

A principle limitation of existing studies is that they assume a storage device has a constant roundtrip efficiency, energy capacity, and power capability, regardless of its instantaneous operating state. While this assumption might not have a strong influence on the overall economic assessment of a given energy storage device, it makes it difficult to connect economic assessments with real-time control to maximize the daily operating revenue of an energy storage device deployed on the grid. To connect operational management of grid energy storage with real-time battery control, we develop an optimization model that uses a flexible behavioral circuit model developed previously [24] to describe the dynamic operating state of a grid battery system and decide how it should charge and discharge to maximize its daily operating revenue without violating its operating constraints.

\section{Battery model transformation}

Chen and Rincón-Mora's model describes the state of a battery using two coupled electrical circuits, as shown in Figure 1 [24]. The "battery lifetime circuit" on the left-hand side of Figure 1 approximates a battery's state of charge based on the current input, $I$. The capacitor $C_{\mathrm{c}}$ integrates the charge flowing into and out of the battery to approximate state of charge, and the resistor $R_{\mathrm{sd}}$ models the effect of self discharge in the absence of an external charging current or float voltage. The circuit components combine to produce a voltage at node $V_{\mathrm{SOC}}$ corresponding to the battery's state of charge. The "voltage-current characteristics circuit" on the right-hand side of Figure 1 estimates the behavior of a battery's terminal voltage, $V$, based on the current input, $I$, and state of charge ( $V_{\mathrm{SOC}}$ from the battery lifetime circuit). The variable potential source $V_{\mathrm{OC}}\left(V_{\mathrm{SOC}}\right)$ models how open-circuit voltage changes with state of charge, and the series resistor $R_{\mathrm{s}}$ and two parallel RC networks consisting of $R_{\mathrm{t}, \mathrm{s}}, C_{\mathrm{t}, \mathrm{s}}, R_{\mathrm{t}, \mathrm{l}}$, and $C_{\mathrm{t}, \mathrm{l}}$ model how the battery's terminal voltage dynamically changes under a variable applied current, $I$, due to the ohmic potential drop and short- and long-term transient reaction dynamics inside the battery. Each of these circuit components has parameters defined by a variable function determined from experimental performance data [24].

Researchers have extracted the parameters required to describe the performance of a number of different batteries using this model. Chen and Rincón-Mora extracted the model parameters for both Li-ion and nickelmetal hydride (Ni-MH) battery cells under various discharge rates [24]. To 
model the performance of a larger battery system, Li, et. al. extracted the model parameters for an Ultralife UBBL10 Li-ion module (consisting of several battery cells) under various discharge rates [28, 29]. To model the effect of temperature on performance, Bauer and Kelder fit the model to a $\mathrm{LiFePO}_{4}$ based Li-ion battery operating at $0{ }^{\circ} \mathrm{C}, 25^{\circ} \mathrm{C}$, and $40^{\circ} \mathrm{C}$ [26]. Similarly, Kim, et. al. fit the model to $100 \mathrm{Ah}$ polymer Li-ion cells of various ages operating at $0{ }^{\circ} \mathrm{C}, 20{ }^{\circ} \mathrm{C}$, and $40{ }^{\circ} \mathrm{C}[27]$.

Because the model developed previously [24] has become popular in the empirical battery modeling literature, we select this model for our analysis. To discretize the model for the purposes of optimization, we use Kirchoff's circuit laws to extract the mathematical equations that describe the dynamic state of the behavioral circuit model components, resulting in the following nonlinear differential equations:

$$
\begin{gathered}
\dot{V}_{S O C}=-\frac{I}{C_{c}}-\frac{V_{S O C}}{R_{s d} C_{c}} \\
\dot{V}_{t, s}=\frac{I}{C_{t, s}}-\frac{V_{t, s}}{R_{t, s} C_{t, s}} \\
\dot{V}_{t, l}=\frac{I}{C_{t, l}}-\frac{V_{t, l}}{R_{t, l} C_{t, l}} \\
V=V_{O C}-I R_{s}-V_{t, s}-V_{t, l}
\end{gathered}
$$

where the circuit components $C_{c}, R_{s d}, C_{t, s}, R_{t, s}, C_{t, l}, R_{t, l}, R_{s}$, and $V_{O C}$ are, theoretically, empirical functions of state of charge $\left(V_{S O C}\right)$, current $(I)$, temperature, and cycle number. However, these parameters can typically be simplified to be independent or linear functions of some variables for specific batteries [24, 26, 27, 28, 29].

To implement Equations 1-4 in an optimization model, we discretize the equations using a forward-difference approximation. Equations 5-8 approximate each of the behavioral circuit state variables at time step $k$ of duration $\Delta t$.

$$
\begin{gathered}
V_{S O C}(k+1)=\left(-\frac{I(k)}{C_{c}(k)}-\frac{V_{S O C}(k)}{R_{s d}(k) C_{c}(k)}\right) \Delta t+V_{S O C}(k) \\
V_{t, s}(k+1)=\left(\frac{I(k)}{C_{t, s}(k)}-\frac{V_{t, s}(k)}{R_{t, s}(k) C_{t, s}(k)}\right) \Delta t+V_{t, s}(k)
\end{gathered}
$$




$$
\begin{gathered}
V_{t, l}(k+1)=\left(\frac{I(k)}{C_{t, l}(k)}-\frac{V_{t, l}(k)}{R_{t, l}(k) C_{t, l}(k)}\right) \Delta t+V_{t, l}(k) \\
V(k)=V_{O C}(k)-I(k) R_{s}(k)-V_{t, s}(k)-V_{t, l}(k)
\end{gathered}
$$

The following section discusses how we integrate the discretized model given above with an optimization model for economic operational management of grid battery energy storage.

\section{Dynamic economic operational management model}

A battery energy storage system can provide a number of different grid applications [37, 49]. Typically, the decision variable for grid operation is the instantaneous level of charging or discharging power flowing between the electric grid and the battery device. The charging or discharging power applied to the battery affects its dependent state variables: current, voltage, and state of charge, all of which must be controlled within acceptable limits during battery operation. The following sections implement an optimization program for optimal storage dispatch, and then demonstrate the capabilities of the program using the example of Li-ion energy storage providing wholesale energy arbitrage in Texas' restructured electricity market.

\subsection{Optimization Model}

To decide how a grid battery should charge and discharge to maximize its operating revenue without violating its operating constraints, we implement the discretized battery model developed in the previous section in a nonlinear optimization program. The objective function of the optimization program depends on the intended energy storage application. In its most general form, the objective function can be written as in Equation 9, with the objective expressed as a function of the power, $P$, flowing between the battery and the grid during each optimization time step, $k$.

$$
\text { Objective }=f\left(P\left(k_{1}\right), \cdots, P\left(k_{n}\right)\right)
$$

We relate the optimization decision variables, $P$, to the dependent state variables $I, V$, and $V_{S O C}$ with the equality constraints of Equations 10-14, which are imposed at each time step, $k$, to encapsulate the dynamics of the circuits shown in Figure 1. 


$$
\begin{aligned}
& \forall k \quad P(k)=I(k) V(k) \\
& \forall k V_{S O C}(k+1)= \begin{cases}V_{S O C, i} & \text { if } k=0 \\
-\frac{I(k)}{C_{c}(k)} \Delta t+V_{S O C}(k) & \text { if } k>0\end{cases} \\
& \forall k \quad V_{t, s}(k+1)= \begin{cases}V_{t, s, i} & \text { if } k=0 \\
\left(\frac{I(k)}{C_{t, s}(k)}-\frac{V_{t, s}(k)}{R_{t, s}(k) C_{t, s}(k)}\right) \Delta t+V_{t, s}(k) & \text { if } k>0\end{cases} \\
& \forall k \quad V_{t, l}(k+1)= \begin{cases}V_{t, l, i} & \text { if } k=0 \\
\left(\frac{I(k)}{C_{t, l}(k)}-\frac{V_{t, l}(k)}{R_{t, l}(k) C_{t, l}(k)}\right) \Delta t+V_{t, l}(k) & \text { if } k>0\end{cases} \\
& \forall k \quad V(k)=V_{O C}(k)-I(k) R_{s}(k)-V_{t, s}(k)-V_{t, l}(k)
\end{aligned}
$$

In addition to equality constraints describing the dynamics of the behavioral circuit model, equality constraints are used to define the behavioral circuit parameters $C_{c}, R_{s d}, C_{t, s}, R_{t, s}, C_{t, l}, R_{t, l}, R_{s}$, and $V_{O C}$, which are described by empirical functions extracted via experiment, as described in the literature [24, 26, 27, 28, 29].

Finally, the inequality constraints of Equations 15-17 are used to bound the relevant state variables within limits established by the battery system operator or battery cell manufacturer.

$$
\begin{gathered}
\forall k \quad I_{\text {charge,max }} \leq I(k) \leq I_{\text {discharge,max }} \\
\forall k \quad V_{\text {min }} \leq V(k) \leq V_{\text {max }} \\
\forall k \quad S O C_{\text {min }} \leq V_{S O C}(k) \leq S O C_{\max }
\end{gathered}
$$

The optimization program developed here can be used to manage the operation of any battery system, provided it has been characterized via experiment, and functions have been developed to describe the empirical circuit parameters $C_{c}, R_{s d}, C_{t, s}, R_{t, s}, C_{t, l}, R_{t, l}, R_{s}$, and $V_{O C}$. The following section implements the optimization program for Li-ion energy storage operating in Texas' restructured electricity to demonstrate the results of the optimization for a particular battery technology and operational context. 


\subsection{Application to lithium-ion energy storage operating in Texas}

The Electric Reliability Council of Texas (ERCOT) operates Texas' electric grid and manages the state's restructured electricity market. Each day, electricity resources submit information to ERCOT, and then ERCOT executes a security-constrained economic dispatch program to minimize overall electricity costs while maintaining electric reliability [50]. By doing so, ERCOT clears the market and establishes an electricity price, which can vary significantly over the day due to variation in electric demand and the availability of electric generation.

Battery energy storage can provide electric energy to ERCOT by performing wholesale energy arbitrage: buying low-cost electricity for later sale during on-peak hours, when the price for electricity is higher. ERCOT accepts interconnection requests from electricity generators and storage devices with a rated power capacity of $10 \mathrm{MW}$ or greater. [51] Even if a storage device is smaller than $10 \mathrm{MW}$, it could be aggregated with other small storage devices by a qualified entity to facilitate its interaction with the ERCOT market. Storage resources that have been accepted for interconnection to ERCOT can purchase charging electricity from and sell stored electricity to the ERCOT electricity market at the corresponding real-time energy price. It is important for the grid battery operator to manage when their system charges and discharges in order to maximize the price difference between charging energy and discharging energy, thereby maximizing operating revenue.

We implement the optimization program discussed in the previous section to manage the operation of a battery system for wholesale energy arbitrage in ERCOT. Because ERCOT establishes a real-time price for electricity every 15 minutes [50], we consider decision variables for every quarter-hour interval, $q$, of the day. The objective function to be maximized is defined in Equation 18, where negative values of $P(q)$ denote charging power, positive values of $P(q)$ denote discharging power, and $\pi(q)$ denotes the price for electricity during price settlement interval $q$ of duration $\Delta t_{q}$.

$$
\text { Objective }=\sum_{q} P(q) \Delta t_{q} \pi(q)
$$

We model the dynamics of the battery system at each time step, $k$, of duration $\Delta t$ using the equality constraints of Equations 11-14, with $\Delta t$ set equal to 10 seconds. Equation 19 is used to bind the dynamic state variables 
$I(k)$ and $V(k)$ to the decision variables $P(q)$.

$$
\forall q, \forall k \in q \quad P(q)=I(k) V(k)
$$

$V_{O C}=-1.031 e^{-35 V_{S O C}}+3.685+0.2156 V_{S O C}-0.1178 V_{S O C}^{2}+0.3201 V_{S O C}^{3} \mathrm{~V}$

$$
C_{c}=3060 \mathrm{~F}
$$

$$
R_{s}=0.1562 e^{-24.37 V_{S O C}}+0.07446 \Omega
$$$$
R_{t, s}=0.3208 e^{-29.14 V_{S O C}}+0.04669 \Omega
$$$$
C_{t, s}=-752.9 e^{-13.51 V_{S O C}}+703.6 \mathrm{~F}
$$$$
R_{t, l}=6.603 e^{-155.2 V_{S O C}}+0.04984 \Omega
$$ 


$$
C_{t, l}=-6056 e^{-27.12 V_{S O C}}+4475 \mathrm{~F}
$$

Specifications for a PL-383562 polymer Li-ion battery cell are available from the manufacturer [52]. We use these specifications to identify values for the operating parameters that define the inequality constraints of Equations 15-17. We consider an operating depth of discharge of $80 \%$, assuming the battery operator would choose to avoid extreme values of state of charge to extend the lifetime of the battery system. The values considered for each of the relevant operating parameters are given in Table 1.

With the objective function, battery model, and operating constraints established, we implement the optimization program in the General Algebraic Modeling System (GAMS) [53]. We consider an operating period of 24 hours, corresponding to the day-ahead operating timeline of the ERCOT market [50]. Thus, the optimization program considers 96 decision variables (the charging or discharging power during each 15-minute price interval, $q$ ) and 8,640 dependent variables (one for each 10-second discretized time step, $k$ ) for each state variable $I, V, V_{S O C}, V_{t, s}, V_{t, l}, V_{O C}, C_{t, s}, R_{t, s}, C_{t, l}, R_{t, l}$, and $R_{s}$. The nonlinear, interior-point optimization algorithm is used to find optimum values for the decision variables based on the price of electricity, $\pi(q)$, entered into the program. We utilize Matlab to prepare ERCOT price data, and then use the GAMS/Matlab link [54] to enter the data to GAMS, and store the results of the optimization routine.

\section{Results and discussion}

To maximize revenue, a battery would provide wholesale energy arbitrage during an operating day with one or more significant electricity price variations. Thus, we select prices from August 21, 2011, shown in the top portion of Figure 2, to illustrate the results of our model. The bottom portion of Figure 2 shows the corresponding value of the decision variables computed by our optimization model. The cell power variable is the real electrical power in $\mathrm{W}$ delivered by a single battery cell building block making up a larger integrated battery system. Positive values of cell power correspond to discharging, while negative values correspond to charging. The fact that the values of this variable returned by our algorithm correspond to charging when the electricity price is low and discharging when the price is high shows that our algorithm responds appropriately to price fluctuations. 
Figure 3 shows the value of dynamic state variables $I, V$, and $V_{S O C}$ approximated by the battery model encapsulated within the optimization program. The dashed lines indicate the inequality constraints corresponding to the operating parameters listed in Table 1. The results of Figure 3 show that our model can be used to plan the operation of grid battery energy storage within operating limits established by the battery manufacturer or battery system operator. This feature is useful because it may be desirable to avoid certain values of battery voltage, current rate, or state of charge in order to extend the lifetime of a battery system.

To calculate the revenue potential of a battery from its optimal chargedischarge schedule, we solve for the AC power, $P_{\text {grid }}$, flowing between the battery and the grid using Equation 27, and then use Equation 28 to calculate the potential revenue from operating on a given day in ERCOT. We assume an inverter $/$ rectifier efficiency $\eta_{\text {AC-DC }}=\eta_{\text {DC-AC }}=93 \%[49,55]$.

$$
\begin{gathered}
P_{\text {grid }}= \begin{cases}\frac{1}{\eta_{\mathrm{AC}-\mathrm{DC}}} P & \text { if charging }(P<0) \\
\eta_{\mathrm{DC}-\mathrm{AC}} P & \text { if discharging }(P>0) \\
0 & \text { if idle }(P=0)\end{cases} \\
R_{\text {day }}=\sum_{q=1}^{96} P_{\text {grid }}(q) \Delta t_{q} \pi(q)
\end{gathered}
$$

A number of normalization methods are used to illustrate the operating revenue of energy storage in a general way. One method is to divide the total operating revenue by the device's rated power to express revenue per unit of power capacity (e.g. $\$ / \mathrm{kW}$ capacity). A second method is to divide the total operating revenue by the device's rated energy capacity to express revenue per unit of energy storage capacity (e.g. $\$ / \mathrm{kWh}$ capacity). A third method that is particularly useful for battery systems prone to degradation is to divide the total operating revenue by the total amount of energy delivered to the grid (e.g. \$/MWh delivered).

Because a Li-ion battery would degrade with each of its charge-discharge cycles, we use the third normalization procedure described above, and calculate the revenue per MWh of energy delivered to the grid according to Equations 29 and 30. The square brackets in Equation 29 indicate that only discharged energy is counted [56], while the braces in Equation 30 indicate units. 


$$
\begin{gathered}
E_{\text {delivered }}^{\text {day }}=\sum_{q=1}^{96} P_{\text {grid }}(q)\left[P_{\text {grid }}(q)>0\right] \Delta t_{q} \\
R_{\mathrm{MWh}}^{\text {day }}=\frac{R_{\text {day }}\{\$ / \text { day }\}}{E_{\text {delivered }}^{\text {day }}\{\mathrm{MWh} / \text { day }\}}
\end{gathered}
$$

A battery system dispatched as in Figure 2 would incur an operating revenue of approximately $\$ 85 / \mathrm{MWh}$ delivered calculated according to the equations above. To understand how the revenue potential of a Li-ion battery system operating for wholesale energy arbitrage in Texas varies from day to day, we solve the optimization problem for each day of 2002-2012 using electricity prices from each of ERCOT's four hubs: North, Houston, South, and West. Figure 4 illustrates our results expressed per MWh of electricity delivered. In each of ERCOT's four trading hubs, the potential revenue from energy arbitrage varies significantly from day to day. The greatest revenue opportunities occurred in 2008, when the average U.S. natural gas price for electricity generation was high (\$9.26/MMBtu [57]), and in 2011, when a combination of extreme temperatures and drought caused high electric demand, constrained electric supply, and high summer electricity prices in the ERCOT region [58].

To approximate the expected revenue from the sale of stored energy on an annual basis, we calculate the revenue per MWh of energy sold annually according to Equations 31 and 32.

$$
\begin{gathered}
E_{\text {delivered }}^{\text {year }}=\sum^{\text {year }} E_{\text {delivered }}^{\text {day }} \\
R_{\mathrm{MWh}}^{\text {year }}=\frac{\left(\sum_{\text {year }}^{\text {year }} R_{\text {day }}\right)\{\$ / \text { year }\}}{E_{\text {delivered }}^{\text {yel }}\{\text { year }\}}
\end{gathered}
$$

Figure 5 shows the average revenue per MWh of energy sold, $R_{\mathrm{MWh}}^{\mathrm{year}}$, during each operating year, as well as the average revenue per MWh of energy sold observed over all of the operating years considered. The height of each bar indicates the average revenue across all ERCOT regions, and the uncertainty bars indicate the range of revenues observed across all regions during a given year.

To approximate the net-present value (NPV) of Li-ion energy storage used for wholesale energy arbitrage in ERCOT, we consider values of lifecycle revenue per unit of energy sold, $R_{\mathrm{MWh}}^{\text {lifecycle }}$, ranging from $\$ 7 / \mathrm{MWh}$ delivered 
to $\$ 62 /$ MWh delivered, the minimum and maximum values observed in Figure 5 , respectively. We use $\$ 27 /$ MWh delivered, the average value observed, as a point estimate. A study by Battke et al. [59] is used to approximate the cost of Li-ion storage. It reviews multiple recent energy storage cost studies to develop a cost confidence interval representing the current state of knowledge among both experts and industry. It approximates the lifecycle cost of Li-ion capital equipment, maintenance, and degradation (battery cell replacement), $C_{\mathrm{MWh}}^{\text {lifecycle }}$, ranges from approximately $\$ 250-1000 / \mathrm{MWh}$ of electricity delivered, with a point estimate of $\$ 560 / \mathrm{MWh}$ delivered. This figure allows for a one-to-one comparison between our revenue estimate and the estimated cost of a Li-ion battery system. Thus, we calculate NPV by taking a simple difference between lifecycle revenue per unit of energy sold, $R_{\mathrm{MWh}}^{\text {lifecycle }}$, and lifecycle cost per unit of energy sold, $C_{\mathrm{MWh}}^{\text {lifecycle }}$. Figure 6 illustrates point estimates and ranges for revenue, cost, and NPV.

As shown in Figure 6, the NPV of Li-ion batteries used in ERCOT for wholesale energy arbitrage and no other energy storage applications is highly negative based on our estimate of revenue potential and cost estimates from the literature [59]. These results indicate that the lifecycle cost of Li-ion battery energy storage would have to decrease to $\$ 10-100 / \mathrm{MWh}$ delivered for revenue from only wholesale energy arbitrage service in ERCOT to achieve a positive NPV.

It is not surprising that NPV is negative for a Li-ion battery system providing only wholesale energy arbitrage service. Numerous techno-economic studies have revealed the fact that most forms of grid energy storage would have to provide more than one service to the grid to achieve a positive NPV [35, 42, 38, 49]. In practice, a Li-ion battery system would incur revenue from other grid services, such as ancillary services, in addition to revenue from wholesale energy arbitrage, the application we consider in detail here. To understand if there are any occasions when it would be valuable for a Li-ion battery plant to provide wholesale energy arbitrage to ERCOT, we examine if there are individual operating days when the potential revenue, $R_{\mathrm{MWh}}^{\text {day }}$, exceeds levelized storage cost, $C_{\mathrm{MWh}}^{\text {lifecycle }}$.

We compare the potential daily operating revenues illustrated in Figure 4 with the lifecycle Li-ion energy storage cost range illustrated in Figure 6. First, we take the average of the results of Figure 4 across all ERCOT regions, and sort the result from greatest to least. Then, we plot the sorted data using a logarithmic scale on the $\mathrm{x}$ - and $\mathrm{y}$-axis. Finally, on the same axes, we plot 
the lifecycle cost, $C_{\mathrm{MWh}}^{\text {lifecycle }}$, range [59] illustrated in Figure 6. These results are illustrated in Figure 7.

The "value-duration curve" illustrated in Figure 7 is useful because it shows how often revenue from wholesale energy arbitrage service in ERCOT is greater than or equal to the lifecycle cost of a Li-ion battery system levelized per unit of energy discharged. During approximately 7-50 days of the 11-year period studied, the price of electricity is so volatile that it would be possible for revenue from wholesale energy arbitrage to exceed the lifecycle cost per unit of energy discharged. This result suggests that a battery operator should consider the degradation-related cost of performing a grid duty cycle, and how that cost compares with the potential revenue from that cycle, so that a storage device capable of providing multiple grid services can be controlled in an economically efficient way.

\section{Conclusion}

In this paper, we transformed a behavioral circuit model that has become a popular tool for predicting the dynamic performance of a number of different battery systems [24, 26, 27, 28, 29]. After extracting the differential equations that describe the dynamics of the model's electric circuit analog, we discretized the model to create an optimization program for economic operational management of a grid battery system. Our optimization program is advantageous because it has the flexibility to manage the operation of any battery system, provided it can be characterized by the model shown in Figure 1. Furthermore, the program can consider any operational context where the decision variable of interest is the instantaneous power flowing to/from the battery system.

In practice, a battery operator could use the methods developed in this paper to control the interaction of their system with the electric grid. First, the battery owner would carry out an experimental procedure to extract the model parameters for their system, as discussed in the literature [24, 26, $27,28,29]$. Then, the extracted behavioral parameters $C_{c}, R_{s d}, C_{t, s}, R_{t, s}$, $C_{t, l}, R_{t, l}, R_{s}$, and $V_{O C}$ would be entered into our optimization program using equality constraints imposed at each optimization time step, $k$. Finally, the optimization problem would be solved to plan the operation of the energy storage device to maximize operating revenue without violating the selected operating constraints. 
To demonstrate the operation of our model, we considered the case of a Li-ion battery system operating for wholesale energy arbitrage in Texas' restructured electricity market, which is administered by ERCOT. Our model robustly computed an optimal charge-discharge schedule to maximize daily revenue without violating the battery's operating constraints during each operating day we modeled. Using our results, we found that the NPV of Li-ion energy storage used for only wholesale energy arbitrage in ERCOT would be very negative. However, our results indicate that there are a handful of high-value operating days where operating revenue from wholesale energy arbitrage might exceed operating cost. This result suggests that a limitation of our optimization model is that it does not consider the materials-degradation "cost" of providing a battery charge-discharge cycle to the electricity market.

In a future publication, we will build upon the model presented here by including the degradation-related cost of charging and discharging within each operational decision considered by the optimization program. By doing so, we hope to show how intelligent operation of a cycle-limited battery device might increase its value. Furthermore, we will augment our operational model to consider the interaction between multiple simultaneous energy storage applications (e.g. wholesale energy arbitrage and ancillary services) and the real-time tradeoff associated with providing one application versus another. By doing so, we hope to reveal a holistic grid battery operation scheme that minimizes battery degradation and maximizes revenue.

\section{Acknowledgments}

This work was sponsored by Pecan Street Inc. of Austin, Texas as part of its ongoing smart grid demonstration project, which is part of the American Recovery and Reinvestment Act Smart Grid Demonstration Program administered by the U.S. Department of Energy. Special thanks to ERCOT for making their historic electricity price data available to the public.

\section{References}

[1] C.-J. Yang, R. B. Jackson, Opportunities and barriers to pumped-hydro energy storage in the United States, Renewable and Sustainable Energy Reviews 15 (1) (2011) 839-844. doi:10.1016/j.rser.2010.09.020.

[2] GE Energy, R. A. Walling, Analysis of Wind Generation Impact on ERCOT Ancillary Services Requirements, Tech. rep., General Electric 
(2008).

URL http://www.uwig.org/attchb-ercot \_a-s \_study \_final _report.pdf

[3] B. Roberts, J. Harrison, Energy Storage Activities in the United States Electricity Grid, Tech. rep., Electricity Advisory Committee (2011).

[4] J. Newman, Electrochemical Systems, Prentice-Hall, 1972.

[5] M. Doyle, J. Newman, A. S. Gozdz, C. N. Schmutz, J.-M. Tarascon, Comparison of Modeling Predictions with Experimental Data from Plastic Lithium Ion Cells, Journal of The Electrochemical Society 143 (6) (1996) 1890. doi:10.1149/1.1836921.

URL http://jes.ecsdl.org/cgi/doi/10.1149/1.1836921

[6] J. Newman, K. E. Thomas, H. Hafezi, D. R. Wheeler, Modeling of lithium-ion batteries, Journal of Power Sources 119-121 (2003) 838-843. doi:10.1016/S0378-7753(03)00282-9.

[7] K. a. Smith, C. D. Rahn, C.-Y. Wang, Control oriented 1D electrochemical model of lithium ion battery, Energy Conversion and Management 48 (9) (2007) 2565-2578. doi:10.1016/j.enconman.2007.03.015.

URL http://linkinghub.elsevier.com/retrieve/pii/ S0196890407000908

[8] D. W. Dees, V. S. Battaglia, A. Bélanger, Electrochemical modeling of lithium polymer batteries, Journal of Power Sources 110 (2) (2002) 310-320. doi:10.1016/S0378-7753(02)00193-3.

URL http://linkinghub.elsevier.com/retrieve/pii/ S0378775302001933

[9] W. Peukert, Über die abhängigkeit der kapazität von der entladestromstärke bei bleiakkumulatoren, Elektrotechnische Zeitschrift 20 (1897) 20-21.

[10] D. Doerffel, S. A. Sharkh, A critical review of using the Peukert equation for determining the remaining capacity of lead-acid and lithium-ion batteries, Journal of Power Sources 155 (2) (2006) 395-400. doi:10.1016/j.jpowsour.2005.04.030. 
[11] D. Rakhmatov, S. Vrudhula, D. Wallach, A model for battery lifetime analysis for organizing applications on a pocket computer, IEEE Transactions on Very Large Scale Integration (VLSI) Systems 11 (6) (2003) 1019-1030. doi:10.1109/TVLSI.2003.819320.

[12] J. F. Manwell, J. G. McGowan, Lead acid battery storage model for hybrid energy systems, Solar Energy 50 (5) (1993) 399-405. doi:10.1016/0038-092X(93)90060-2.

[13] P. Rong, S. Member, M. Pedram, An Analytical Model for Predicting the Remaining Battery Capacity of Lithium-Ion Batteries, IEEE Transactions on Very Large Scale Integration (VLSI) Systems 14 (5) (2006) 441-451.

[14] P. Pascoe, A. Anbuky, VRLA Battery Discharge Reserve Time Estimation, IEEE Transactions on Power Electronics 19 (6) (2004) 1515-1522. doi:10.1109/TPEL.2004.836680.

[15] V. Agarwal, K. Uthaichana, Development and Validation of a Battery Model Useful for Discharging and Charging Power Control and Lifetime Estimation, IEEE Transactions on Energy Conversion 25 (3) (2010) 821835 .

[16] Z. Salameh, M. Casacca, W. Lynch, A mathematical model for lead-acid batteries, IEEE Transactions on Energy Conversion 7 (1) (1992) 93-98. doi:10.1109/60.124547.

[17] L. Gao, S. Liu, R. A. Dougal, Dynamic lithium-ion battery model for system simulation, IEEE Transactions on Components and Packaging Technologies 25 (3) (2002) 495-505. doi:10.1109/TCAPT.2002.803653.

[18] M. Valvo, F. E. Wicks, R. Douglas, S. Rudiii, Development and Appliication of an Improved Equivalent Circuit Model of a Lead Acid Blattery, Proceedings of the 31st Intersociety Energy Conversion Engineering Conference.

[19] P. Mauracher, E. Karden, Dynamic Modeling of lead/acid batteries using impedance spectroscopy for parameter identification, Journal of Power Sources 67 (1997) 69-84. 
[20] H. Wiegman, A. Vandenput, Battery state control techniques for charge sustaining applications, SAE transactions (1999) 1-11.

[21] S. Buller, M. Thele, Impedance-based simulation models of supercapacitors and Li-ion batteries for power electronic applications, IEEE Transactions on Industry Applications 41 (3) (2005) 742-747.

[22] S. Gold, A PSPICE macromodel for lithium-ion batteries, The Twelfth Annual Battery Conference on Applications and Advances (1997) 215222doi:10.1109/BCAA.1997.574106.

[23] S. Hageman, Simple pspice models let you simulate common battery types, EDN 38 (1993) 117-117.

[24] M. Chen, G. Rincon-Mora, Accurate electrical battery model capable of predicting runtime and IV performance, IEEE Transactions on Energy Conversion 21 (2) (2006) 504-511.

[25] R. C. Kroeze, P. T. Krein, Electrical battery model for use in dynamic electric vehicle simulations, 2008 IEEE Power Electronics Specialists Conference (2008) 1336-1342doi:10.1109/PESC.2008.4592119.

URL http://ieeexplore.ieee.org/lpdocs/epic03/wrapper.htm? arnumber $=4592119$

[26] P. Bauer, E. Kelder, A practical circuit-based model for Li-ion battery cells in electric vehicle applications, 2011 IEEE 33rd International Telecommunications Energy Conference (INTELEC) (2011) 1-9doi:10.1109/INTLEC.2011.6099803.

URL http://ieeexplore.ieee.org/lpdocs/epic03/wrapper.htm? arnumber $=6099803$

[27] B. G. Kim, D. D. Patel, Z. M. Salameh, Circuit Model of 100 Ah Lithium Polymer Battery Cell, Journal of Power and Energy Engineering 01 (06) (2013) 1-8. doi:10.4236/jpee.2013.16001.

[28] J. Li, M. Mazzola, J. Gafford, N. Younan, A new parameter estimation algorithm for an electrical analogue battery model, 2012 TwentySeventh Annual IEEE Applied Power Electronics Conference and Exposition (APEC) (2012) 427-433doi:10.1109/APEC.2012.6165855.

URL http://ieeexplore.ieee.org/lpdocs/epic03/wrapper.htm? arnumber $=6165855$ 
[29] J. Li, M. S. Mazzola, J. Gafford, B. Jia, M. Xin, Bandwidth based electrical-analogue battery modeling for battery modules, Journal of Power Sources 218 (2012) 331-340. doi:10.1016/j.jpowsour.2012.07.006. URL http://linkinghub.elsevier.com/retrieve/pii/ S0378775312011202

[30] B. Schweighofer, K. M. Raab, G. Brasseur, Modeling of High Power Automotive Batteries by the Use of an Automated Test System, IEEE Transactions on Instrumentation and Measurement 52 (4) (2003) 10871091.

[31] S. Abu-Sharkh, D. Doerffel, Rapid test and non-linear model characterisation of solid-state lithium-ion batteries, Journal of Power Sources 130 (1-2) (2004) 266-274. doi:10.1016/j.jpowsour.2003.12.001.

[32] I. Gyuk, P. Kulkarni, J. Sayer, J. Boyes, G. Corey, G. Peek, The united states of storage, IEEE Power and Energy Magazine 3 (2) (2005) 31 39. doi:10.1109/MPAE.2005.1405868.

[33] S. M. Schoenung, J. M. Eyer, J. J. Iannucci, S. A. Horgan, Energy Storage for a Competitive Power Market, Annual Review of Energy and the Environment 21 (1) (1996) 347-370. doi:10.1146/annurev.energy.21.1.347.

URL http://arjournals.annualreviews.org/doi/abs/10.1146\ $\% 2$ Fannurev. energy.21.1.347

[34] P. C. Butler, J. Iannucci, J. Eyer, Innovative Business Cases For Energy Storage In a Restructured Electricity Marketplace, Tech. Rep. February, Sandia National Laboratories (2003).

[35] A. Zucker, T. Hinchliffe, A. Spisto, Assessing Storage Value in Electricity Markets: A literature review, Tech. rep., European Commission Joint Research Centre (2013). doi:10.2790/89242.

[36] J. Eyer, B. Norris, Guide to Estimating Benefits and Market Potential for Electricity Storage in New York, Tech. rep. (2007).

[37] J. Eyer, G. Corey, Energy Storage for the Electricity Grid: Benefits and Market Potential Assessment Guide A Study for the DOE Energy Storage Systems Program, Tech. Rep. February, Sandia National Laboratories (2010). 
[38] R. Walawalkar, J. Apt, R. Mancini, Economics of electric energy storage for energy arbitrage and regulation in New York, Energy Policy 35 (4) (2007) 2558-2568. doi:10.1016/j.enpol.2006.09.005.

[39] S. J. Kazempour, M. P. Moghaddam, M. R. Haghifam, G. R. Yousefi, Electric energy storage systems in a market-based economy: Comparison of emerging and traditional technologies, Renewable Energy 34 (12) (2009) 2630-2639. doi:10.1016/j.renene.2009.04.027.

URL http://linkinghub.elsevier.com/retrieve/pii/ S0960148109001906

[40] C. K. Ekman, S. r. H. j. Jensen, Prospects for large scale electricity storage in Denmark, Energy Conversion and Management 51 (6) (2010) 1140-1147. doi:10.1016/j.enconman.2009.12.023.

URL http://linkinghub.elsevier.com/retrieve/pii/ S0196890409005299

[41] R. Sioshansi, P. Denholm, T. Jenkin, J. Weiss, Estimating the value of electricity storage in PJM: Arbitrage and some welfare effects, Energy Economics 31 (2) (2009) 269-277. doi:10.1016/j.eneco.2008.10.005.

[42] X. He, E. Delarue, W. D'haeseleer, J.-M. Glachant, A novel business model for aggregating the values of electricity storage, Energy Policy 39 (3) (2011) 1575-1585. doi:10.1016/j.enpol.2010.12.033.

URL http://linkinghub.elsevier.com/retrieve/pii/ S030142151000933X

[43] X. He, R. Lecomte, A. Nekrassov, E. Delarue, E. Mercier, Compressed air energy storage multi-stream value assessment on the french energy market, in: 2011 IEEE Trondheim PowerTech, IEEE, 2011, pp. 1-6. doi:10.1109/PTC.2011.6019395.

URL http://ieeexplore.ieee.org/lpdocs/epic03/wrapper.htm? arnumber $=6019395$

[44] E. Drury, P. Denholm, R. Sioshansi, The value of compressed air energy storage in energy and reserve markets, Energy 36 (8) (2011) 4959-4973. doi:10.1016/j.energy.2011.05.041.

URL http://linkinghub.elsevier.com/retrieve/pii/ S0360544211003665 
[45] P. Balducci, W. Colella, M. Elizondo, C. Jin, T. Nguyen, V. Viswanathan, Y. Zhang, National Assessment of Energy Storage for Grid Balancing and Arbitrage: Phase 1, WECC, Tech. Rep. June, Pacific Northwest National Laboratory (2012).

URL http://energyenvironment.pnnl.gov/pdf/PNNL-21388\ _National \_Assessment \_Storage \_Phase \_1 \_final.pdf

[46] D. Keles, R. Hartel, D. Most, W. Fichtner, Compressed-air energy storage power plant investments under uncertain electricity prices: an evaluation of compressed-air energy storage plants in liberalized energy markets, The Journal of Energy Markets 5 (1).

[47] H. Lund, G. Salgi, B. Elmegaard, a. Andersen, Optimal operation strategies of compressed air energy storage (CAES) on electricity spot markets with fluctuating prices, Applied Thermal Engineering 29 (5-6) (2009) 799-806. doi:10.1016/j.applthermaleng.2008.05.020. URL http://linkinghub.elsevier.com/retrieve/pii/ S1359431108002469

[48] A. A. Akhil, G. Huff, A. B. Currier, B. C. Kaun, D. M. Rastler, S. B. Chen, A. L. Cotter, D. T. Bradshaw, W. D. Gauntlett, DOE/EPRI 2013 Electricity Storage Handbook in Collaboration with NRECA, Tech. Rep. July, Sandia National Laboratories (2013).

[49] I. Gyuk, S. Eckroad, U.S. Department of Energy, The Electric Power Research Institute, EPRI-DOE Handbook of Energy Storage for Transmission \& Distribution Applications, Tech. Rep. December, EPRI-DOE (2003).

[50] ERCOT, ERCOT Nodal Protocols (2014).

[51] T. E. R. C. of Texas, ERCOT Planning Guide Section 5: Generation Resource Interconnection or Change Request (March 2014). URL http://www. ercot.com/mktrules/guides/planning/current

[52] AA Portable Power Corporation, PL-383562 Specifications (2003). URL http://www . batteryspace.com/prod-specs/PL383562.pdf

[53] R. E. Rosenthal, GAMS Development Corporation, GAMS A Users Guide (2012).

URL http://www . gams . com/dd/docs/bigdocs/GAMSUsersGuide.pdf 
[54] M. C. Ferris, R. Jain, S. Dirkse, GDXMRW : Interfacing GAMS and MATLAB (2011).

URL http://www.gams. com/dd/docs/tools/gdxmrw.pdf

[55] H. Bindner, C. Ekman, O. Gehrke, F. Isleifsson, Characterization of Vanadium Flow Battery, Tech. rep., Riso DTU National Laboratory for Sustainable Energy (2010).

[56] D. E. Knuth, Two notes on notation (1992) 1-23arXiv:9205211.

URL http://arxiv.org/abs/math/9205211

[57] U.S. Energy Information Administration - Natural Gas.

URL http://www.eia.gov/naturalgas/

[58] Potomac Economics, 2011 State of the Market Report for the ERCOT Wholesale Electricity Markets, Tech. Rep. July (2012).

URL http://www. potomaceconomics.com/uploads/ercot $\backslash$ _documents/2011\_ERCOT\_SOM \_REPORT .pdf

[59] B. Battke, T. S. Schmidt, D. Grosspietsch, V. H. Hoffmann, A review and probabilistic model of lifecycle costs of stationary batteries in multiple applications, Renewable and Sustainable Energy Reviews 25 (2013) 240-250. doi:10.1016/j.rser.2013.04.023.

URL http://linkinghub.elsevier.com/retrieve/pii/ S136403211300275X 


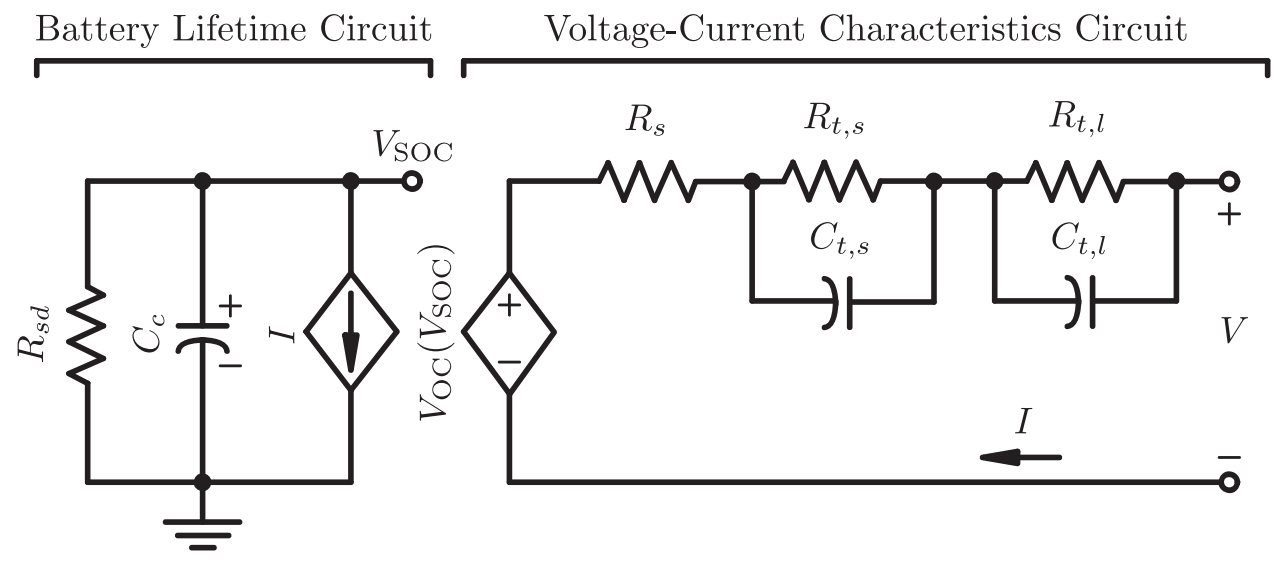

Figure 1: The battery lifetime circuit describes the dynamic nature of a battery's state of charge, and the voltage-current characteristics circuit describes how the terminal voltage of a battery is dynamically affected by state of charge and current load. Figure adapted from [24]. 


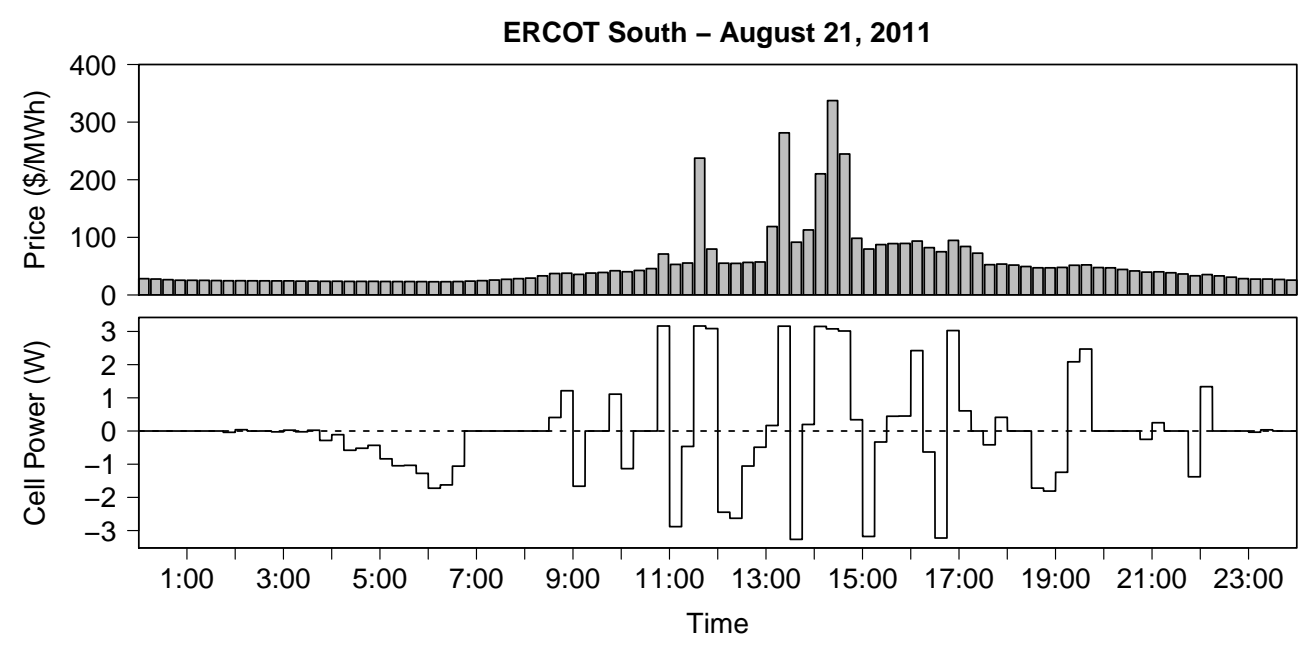

Figure 2: The optimization model decides when a battery should charge and discharge to maximize its operating revenue from wholesale energy arbitrage in Texas' ERCOT electricity market. The plots shown here illustrate the optimal charge-discharge schedule on August 21, 2011 in ERCOT's southern hub, with positive values of power indicating discharge. 

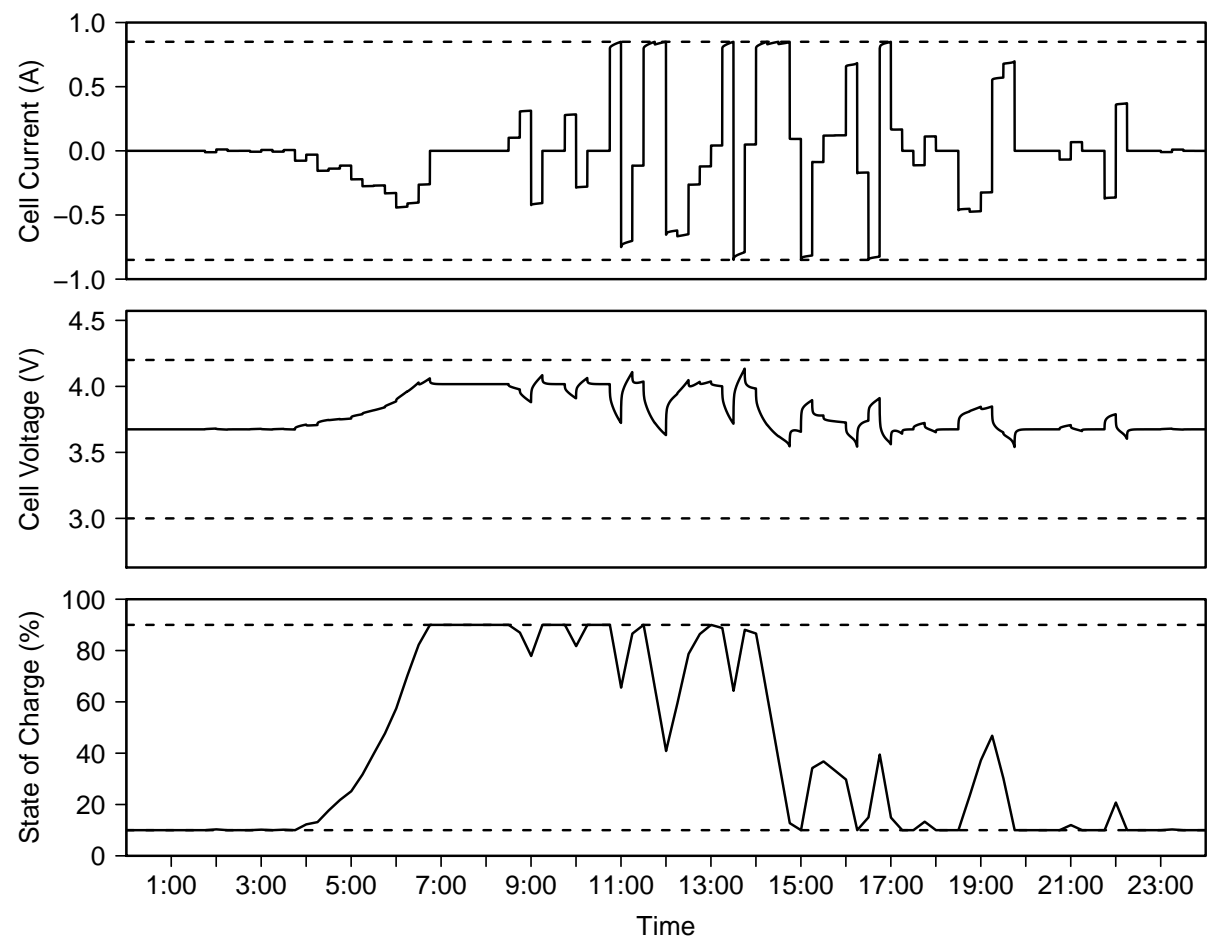

Figure 3: The optimization model encapsulates an empirical, dynamic battery model to approximate battery state variables during each 10 -second optimization time step. This figure shows the dynamic state corresponding to the charge-discharge schedule shown in Figure 2. The dashed lines in each plot indicate the operating parameter limits established in Table 1. 

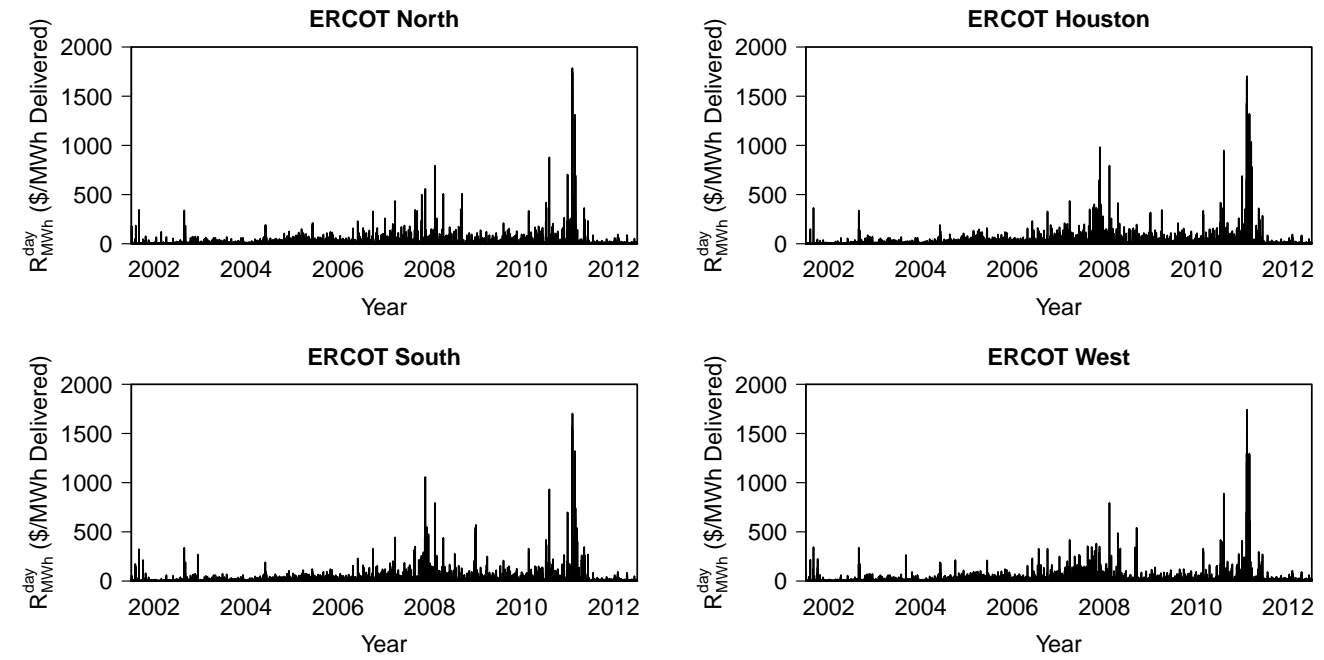

Figure 4: In each of ERCOT's four trading hubs, the potential revenue from energy arbitrage varies significantly from day to day. The greatest revenue opportunities occurred when natural gas prices were high (2008) and electricity resources were scarce (2011). 


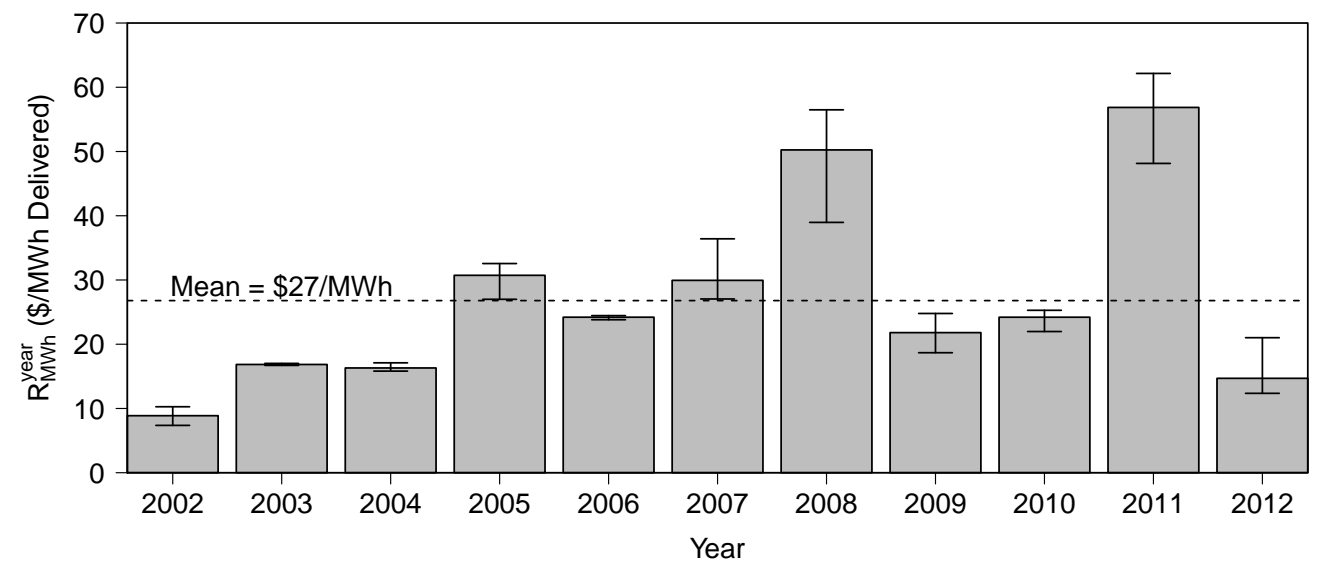

Figure 5: We calculate the revenue per unit of energy sold during each operating year considered according to Equations 31 and 32 . The height of each bar indicates the average revenue across all ERCOT regions, and the uncertainty bars indicate the range of revenues observed across all regions during a given year. The potential revenue varies significantly from one year to another. 


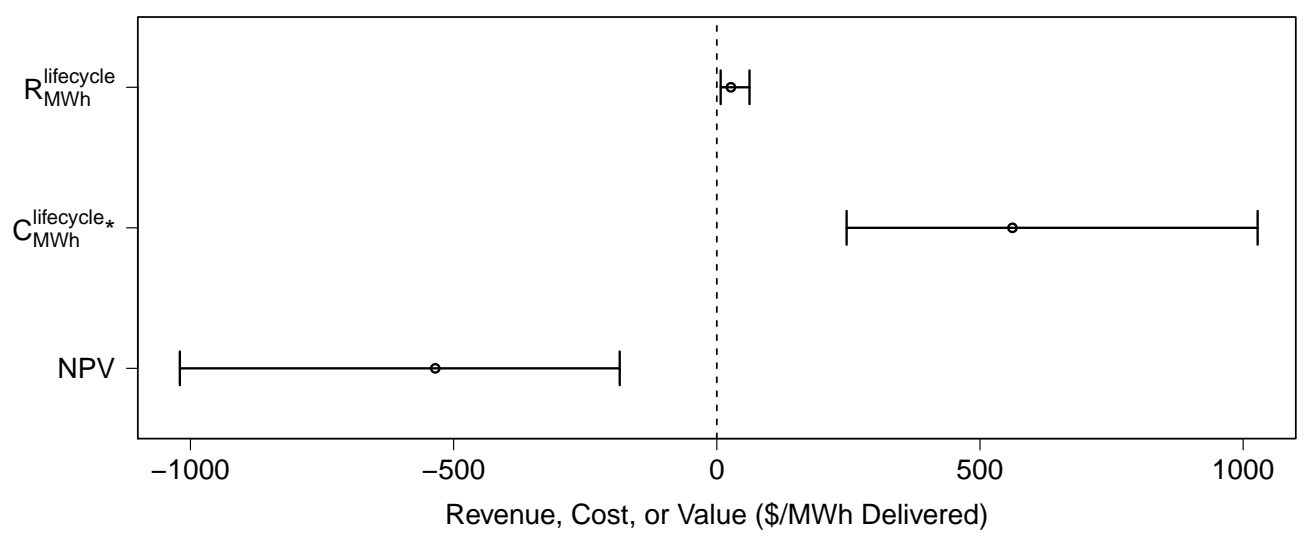

*: From [59]. Includes the cost of Li-ion battery capital equipment, maintenance, and degradation. Excludes the cost of purchased charging energy.

Figure 6: The lifecycle cost of storing electricity in Li-ion batteries, $C_{\mathrm{MWh}}^{\text {lifecycle }}$, is much greater than the potential revenue from wholesale energy arbitrage in ERCOT, $R_{\mathrm{MWh}}^{\text {lifecycle }}$. This fact causes NPV to be very negative. 


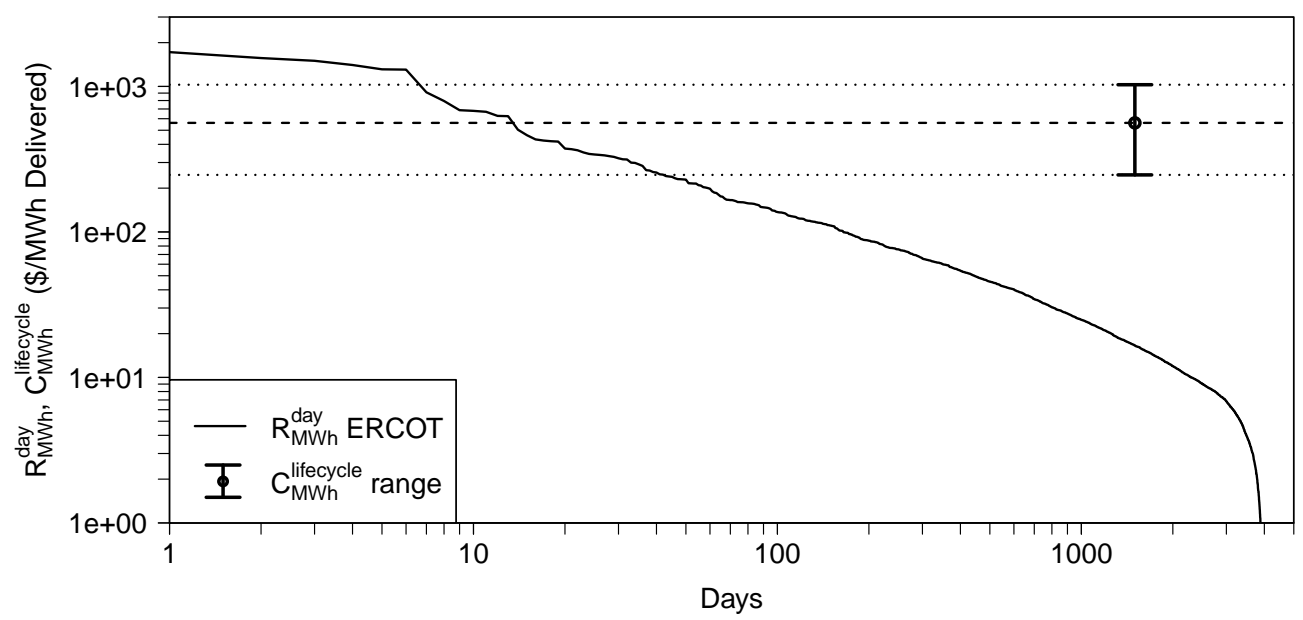

Figure 7: Despite the fact that a Li-ion battery used for only wholesale energy arbitrage in ERCOT could not recoup its costs on average, there are approximately 7-50 days during the 11-year period studied when the revenue per MWh of energy discharged exceeds the lifecycle battery system cost per MWh of energy discharged. 
Table 1: We establish values for the operating parameters that define the inequality constraints of Equations 15-17 based on specifications provided by the battery cell manufacturer [52].

\begin{tabular}{lr}
\hline Operating Parameter & Value \\
\hline$I_{\text {charge, } \max }$ & $850 \mathrm{~mA}$ \\
$I_{\text {discharge,max }}$ & $850 \mathrm{~mA}$ \\
$V_{\min }$ & $3.0 \mathrm{~V}$ \\
$V_{\max }$ & $4.2 \mathrm{~V}$ \\
$S O C_{\min }$ & $10 \%$ \\
$S O C_{\max }$ & $90 \%$ \\
\hline
\end{tabular}

